\title{
To Investigate or Not to Investigate? Researchers' Views on Unexplored Atmospheric Light Phenomena
}

OPEN ACCESS

Edited by: Ismail Gultepe, Environment Canada, Canada

Reviewed by: Ilan Koren,

Weizmann Institute of Science, Israel Miriam Sinnhuber, Karlsruhe Institute of Technology, Germany

${ }^{*}$ Correspondence: Etienne Caron caron@imsb.biol.ethz.ch

Specialty section: This article was submitted to Atmospheric Science, a section of the journal

Frontiers in Earth Science

Received: 09 November 2015 Accepted: 08 February 2016 Published: 24 February 2016

Citation: Caron E and Faridi P (2016) To Investigate or Not to Investigate? Researchers' Views on Unexplored Atmospheric Light Phenomena. Front. Earth Sci. 4:17. doi: 10.3389/feart.2016.00017
Etienne Caron ${ }^{1 *}$ and Pouya Faridi ${ }^{2}$

${ }^{1}$ Department of Biology, Institute of Molecular Systems Biology, ETH Zürich, Zurich, Switzerland, ${ }^{2}$ Department of Phytopharmaceuticals, School of Pharmacy and Pharmaceutical Sciences Research Center, Shiraz University of Medical Sciences, Shiraz, Iran

For hundreds of years, scientists have been studying light, which is used nowadays to explore the universe and cure diseases. Here, we present the results of a survey indicating a significant support from a subset of the academic community to investigate rare, unusual and unexplained atmospheric light phenomena that have historically been unexplored by scientists - the transient luminous phenomena in the valley of Hessdalen in Norway in particular. We propose that stable, long-term funding, and thorough investigation of poorly understood and/or unexplored luminous phenomena occurring in the low atmosphere could lead to the creation of new inter-disciplinary research programs in multiple universities, and ultimately, to important fundamental discoveries in the field of atmospheric science, photonics and beyond.

Keywords: atmospheric, Hessdalen lights, plasma, academic community, funding, photonics, UAP/UFO

"One never notices what has been done; one can only see what remains to be done." Marie Skłodowska Curie (1894)

\section{INTRODUCTION}

Rare and unusual atmospheric lights have been reported in the valley of Hessdalen in Norway for over a century (Zou, 1995; Hauge, 2010). In spite of their irregular occurrence-i.e., 15 to 20 times per week from 1981 to 1984 and 10 to 20 times per year nowadays - the Hessdalen lights (HL) have been consistently observed and possess a series of recurring features: (1) they have the appearance of a free-floating light ball with dimensions ranging from decimeters up to $30 \mathrm{~m}$ (see Figure 1A for a visualization of the visible light spectrum), (2) they are characterized by geometric structures that are often accompanied by small, short-duration pulsating "spikes" in the high frequency and very low frequency radio ranges, (3) they show an absolute luminosity that has been estimated to be 19 $\mathrm{kW}$, and (4) they have a time duration ranging from seconds to hours (Teodorani, 2004; Hauge, 2010; Paiva and Taft, 2012a). HL are also characterized by the formation of light ball clusters and the ejection of mini light balls (Paiva and Taft, 2012b). They may also show very high velocities (i.e., $8000-9000 \mathrm{~m} / \mathrm{s}$, Strand, 1990). Furthermore, HL are thunderstorm-independent events, as opposed to other rare and poorly understood transient luminous phenomena occurring in the atmosphere (i.e., ball lightings Lowke et al., 2012; Cen et al., 2014, blue jets Pasko and George, 2002, red sprites Pasko et al., 2000, and terrestrial gamma-ray flashes Paiva, 2009; Cummer et al., 2014).

Physicists have suggested few models to account for the HL phenomena. One possible explanation attributes the phenomena to an incompletely understood combustion process in the air involving clouds of dust from the valley floor containing scandium (Hauge, 2007, 2010). Another 


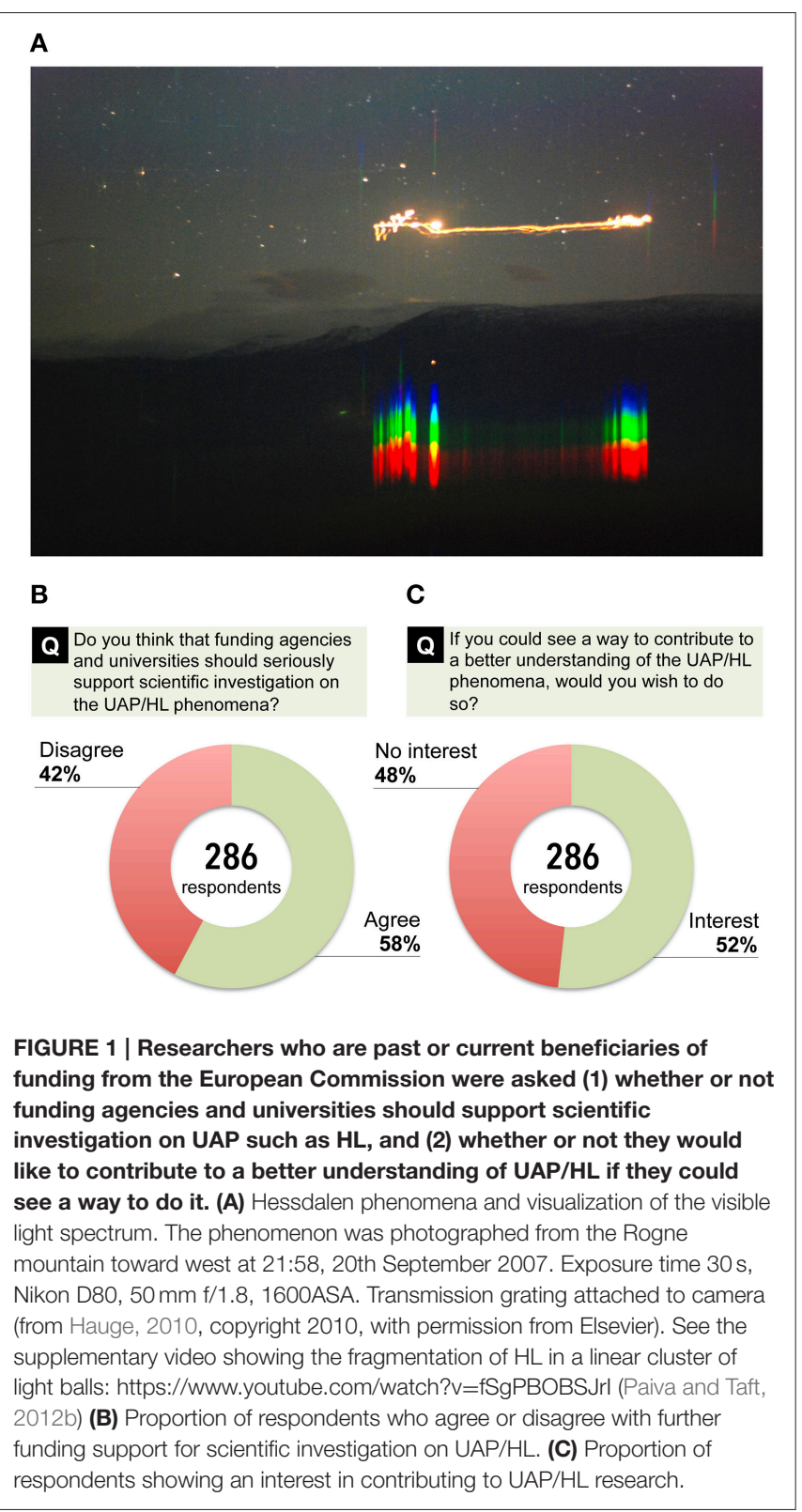

hypothesis suggests that HL are formed by a cluster of macroscopic Coulomb crystals in a dusty plasma produced by the ionization of air and dust by alpha particles during radon decay in the atmosphere (Paiva and Taft, 2010). The valley's shape, microclimate or unique geology might also act as a giant battery that powers the lights (Monari, 2013). Until recently, none of the hypothesis/models described above seems to account for all the observations of HL and the very high energy source generating HL remains completely unknown. In our opinion, most has yet to be discovered about the nature and origin of these infrequent and unusual lights. Given the importance of the science of light (Graydon, 2006), we anticipate that unveiling the mechanism that governs their formation might ultimately be exploited to recreate them, thereby potentially impacting on the field of photonics and light-based technologies.
Historically, HL have received very little attention from the academic community and only a handful of researchers have managed to identify the necessary resources to study the atmospheric "anomaly" and communicate their findings in academic journals (Smirnov, 1994; Zou, 1995; Teodorani, 2004; Hauge, 2010; Paiva and Taft, 2010, 2012a,b). One of the reasons has been the misleading association of HL with the controversial "unidentified flying object" (UFO) phenomena (Appelle, 1998; Kestenbaum, 1998), an association that has nevertheless been disproven by the referred-to frequent, rigorous observation of the phenomena. Interestingly, similar unexplained atmospheric light phenomena (UAP) have recently been measured in Mexico and USA (Hauge and Strand, 2014). Although less frequent than $\mathrm{HL}$, these recent measurements might suggest that this type of luminous phenomena occurring in the low atmosphere is more global than previously anticipated.

\section{ASSESSING RESEARCHERS' OPINIONS ON UAP/HL}

To potentially accelerate the development of innovative photonic/light-based technologies from breakthrough discoveries on the unexplained light phenomena described above, we reasoned that it was timely to assess the opinions of researchers about UAP that have historically been frowned upon by scientists. UAP may include HL as well as other types of "UFO-like" events that have been ignored or rejected by most scientists, although described by a panel of academic scientists to be worthy of study (Sturrock, 1998, 1999). More specifically, we thought that assessing and understanding the opinions of the academic community about UAP might stimulate discussions among scientists and policy makers toward future funding support for the scientific investigation of UAP, HL in particular. Hence, we conducted a study and asked the following elementary question: are researchers within the academic community interested in understanding the nature and origin of unexplored and/or poorly understood luminous phenomena occurring in the low atmosphere such as HL? More precisely, we asked whether or not funding agencies (public and/or private) and universities should seriously support rigorous scientific investigation of UAP that have traditionally been neglected by the academic community?

To assess the interest of the academic community in understanding the atmospheric light phenomenon described above, a survey was systematically sent to 6049 researchers who are past or current beneficiaries of funding from the European Commission (Supplementary Table 1). These researchers originate from 90 countries, are currently distributed across 100 international institutions (primarily in Europe), and are active in various research fields. Participant training and background vary widely and included fields such as astronomy and planetary science, physics, earth and environmental science, chemistry, engineering, materials science, biology, medicine, and business. Participants' ages and career stages also cover a large range including $\mathrm{PhD}$ students, Postdoctoral Fellows, Research Assistants, Assistant Professors, Associate Professors 
and Professors (Supplementary Table 1). Participants were invited by email to read a short article entitled "Scientific Investigation on UAP" (Caron, 2015) before responding anonymously to the online questions. Of the 6049 participants, 295 completed the survey for a participation rate of $\sim 5 \%$ and 286 responded to the question about funding and contribution (Supplementary Table 2). Of note, participation rates for webbased surveys were noted to be as low as 2\% (Monroe and Adams, 2012) while the average response rate for this category of survey was reported to be $\sim 51 \%$ (Archer, 2008). One possible explanation for the low response rate in this study could be that the topic is not a sensitive issue for most scientists and that the response is biased to scientists interested in the topic. Therefore, it is important to mention that any results and conclusions from this study cannot be systematically extrapolated to the opinion of the academic community as a whole.

In this study, our data show that a clear majority of respondents $(58 \%, 165 / 286)$ think that research on UAP should not be neglected and should be supported by funding agencies (Figure 1B). In addition, 52\% (148/286) of respondents would like to contribute to a better understanding of UAP if they could see a way to do it (Figure 1C). Collectively, these results indicate for the first time a significant interest from a subset of scientists to better understand rare and unexplained atmospheric light phenomena that have traditionally been unexplored.

\section{WHO ARE THE ADVOCATES?}

We asked the participants whether funding agencies and universities should support scientific investigation on UAP, HL in particular. Participants trained in the field of physics, astronomy and planetary sciences were significantly less supportive for funding UAP/HL research as compared to those trained in the field of biology and medicine [ 41 vs. $66 \%$, odd ratio $(O R)=2.78$, $p=0.004]$ or those trained in the field of chemistry, engineering and materials science ( 41 vs. $61 \%, \mathrm{OR}=2.25, p=0.016$ ) (Table 1). We also asked the participants to estimate the total number of hours they have spent reading or otherwise informing themselves about UAP. Most respondents (80\%) indicated to have informed themselves for less than $7 \mathrm{~h}$ (Table 1 and Supplementary Table 3). Interestingly, those who have informed themselves for more than $7 \mathrm{~h}$ are significantly more interested in contributing to a better understanding of UAP compared to those who have informed themselves for less than $1 \mathrm{~h}$ (73 vs. $44 \%$, OR $=3.49, p<0.001$; Supplementary Table 3 ). Also, young respondents classified as members of the Generation $\mathrm{X}$ and/or Millennials (i.e., from 21 to 40 years old) were significantly more interested in understanding the nature of unusual atmospheric light phenomena ( $p<0.05$; Supplementary Table 3).

Thus, our data indicate that age, scientific background, and level of knowledge about UAP/HL are relevant factors that, in some way, contribute to shaping the opinions of researchers in this survey. Given the interest of younger researchers, our results also led us to propose that next-generation scientists are more likely to be the main contributors to advance this new field of research, if properly funded in the future.
TABLE 1 | Researcher's views on funding research for the scientific investigation of UAP/HL.

\begin{tabular}{|c|c|c|c|c|c|}
\hline \multicolumn{2}{|r|}{ Variable (n) } & \multirow{2}{*}{$\begin{array}{c}\text { Disagree } \\
44 \%\end{array}$} & \multirow{2}{*}{$\begin{array}{l}\text { Agree } \\
56 \%\end{array}$} & \multirow{3}{*}{$\begin{array}{l}\text { OR } \\
1.32\end{array}$} & \multirow{3}{*}{$\frac{\boldsymbol{p} \text {-value }}{0.438}$} \\
\hline Age & $<31(66)$ & & & & \\
\hline & & $(29 / 66)$ & $(37 / 66)$ & & \\
\hline & $31-40(159)$ & $38 \%$ & $62 \%$ & 1.66 & 0.095 \\
\hline & & $(61 / 159)$ & (98/159) & & \\
\hline & $>40(61)$ & $51 \%$ & $49 \%$ & 1 & - \\
\hline & & $(31 / 61)$ & (30/61) & & \\
\hline \multirow[t]{6}{*}{ Hours $^{a}$} & $<1(149)$ & $45 \%$ & $55 \%$ & 1 & - \\
\hline & & $(67 / 149)$ & $(82 / 149)$ & & \\
\hline & 1-7 (78) & $44 \%$ & $56 \%$ & 1.06 & 0.843 \\
\hline & & $(34 / 78)$ & $(44 / 78)$ & & \\
\hline & $>7(56)$ & $34 \%$ & $66 \%$ & 1.59 & 0.155 \\
\hline & & $(19 / 56)$ & $(37 / 56)$ & & \\
\hline \multirow[t]{5}{*}{ Field } & $\begin{array}{l}\text { Astronomy, physics, earth } \\
\text { and environmental } \\
\text { science (58) }\end{array}$ & $\begin{array}{c}59 \% \\
(34 / 58)\end{array}$ & $\begin{array}{c}41 \% \\
(24 / 58)\end{array}$ & 1 & - \\
\hline & $\begin{array}{l}\text { Chemistry, engineering } \\
\text { and materials science } \\
(101)^{\star}\end{array}$ & $\begin{array}{c}39 \% \\
(39 / 101)\end{array}$ & $\begin{array}{c}61 \% \\
(62 / 101)\end{array}$ & 2.25 & 0.016 \\
\hline & $\begin{array}{l}\text { Medicine and biology } \\
(77)^{\star \star}\end{array}$ & $\begin{array}{c}34 \% \\
(26 / 77)\end{array}$ & $\begin{array}{c}66 \% \\
(51 / 77)\end{array}$ & 2.78 & 0.004 \\
\hline & Business and others (50) & $44 \%$ & $56 \%$ & 1.8 & 0.131 \\
\hline & & $(22 / 50)$ & $(28 / 50)$ & & \\
\hline
\end{tabular}

Question asked: do you think that funding agencies and universities should seriously support scientific investigation on the UAP/HL phenomena? ${ }^{*} p<0.05$; ${ }^{* *} p<0.005$ : odd ratio $(O R)$.

a Total number of hours estimated by each respondent to have spent reading of otherwise informing himself about the UAP phenomena.

\section{FUNDING RESEARCH ON UNEXPLORED ATMOSPHERIC LIGHT PHENOMENA}

Research on UAP/HL is still in a very early stage. Until recently, only a small group of French, Italian and Norwegian researchers have been back to the valley of Hessdalen each September since 2000 to collect data on the phenomena as a sideline to their main research. A program called "Science Camp" was also started in 2002 in which students, teachers and researchers are conducting studies for a period of 14 days. Within this 2 -week timeframe, three mountain bases are equipped with large tents and instruments, making possible the correlation between optical sightings and instrumental data (see Hauge, 2010 for a detailed description of the instruments used and the results that were obtained during the Science Camps).

Interestingly, UAP data recently obtained from other sites in the world were noted to correlate with the characteristics of HL, suggesting that the mechanism creating the phenomena might be global and not only localized to the Hessdalen valley. However, we believe that further research from multiple inter-disciplinary research groups will be crucial to constantly and rigorously acquire accurate, quantitative and reproducible measurements, 
which have been so far to scarce to explain the transient luminous phenomena. Given the infrequent nature of UAP/HL, new state-of-the-art automated stations continuously recording data will also be instrumental for measuring the phenomena. Within those automated stations, it should be possible for instance to use high-quality, high-sensitivity and all-sky video cameras, high-speed recordings, low and high-resolution optical spectrographs, thermal imaging cameras, magnetometers, VLF/ELF and microwave spectrometers, radars, LIDARs, electrostatic particle detectors and gravimeters. Furthermore, next-generation physicists, geologists and engineers might be important contributors to advance the field. In this regard, new training and inter-disciplinary research networks and programs will be needed to build up a community and to communicate scientific information through workshops, conferences and other fora.

Photonic/light-based technologies have major impact on the world economy with a projected market value of $€ 650$ billion in $2020^{1}$. Horizon 2020 is the largest EU Research and Innovation program and has recently implemented Photonics through a Public Private Partnership (PPP)—with 1.6 billion euros foreseen for both photonics and micro- and nanoelectronics ${ }^{2}$. Funding research on HL through such programs could therefore represent an opportunity in the future to advance our understanding of the unusual luminous phenomena. In addition, philanthropy could provide support for the investigation of UAP/HL. In fact, the philanthropic market now accounts for $30 \%$ of science funding at the top 50 US research universities (Bristish Broadcasting Corp., 2014; Broad W. J., 2014). This is exemplified by Wendy and Eric Schmidt who have been giving more than US\$100 million to advance ocean studies; and more recently by Yuri Milner who announced the launch of a bold US\$100 million project to reinvigorate the search for life in the universe (Merali, 2015). Similarly, the UAP/HL phenomena could represent an opportunity for philanthropists interested in focusing their donations on photonics, energy and the development of light-based technologies.

Thus, current research on UAP/HL is relatively modest and one could argue that massive and constant public and/or private

\footnotetext{
${ }^{1}$ http://www.photonics21.org/download/Photonics_industry_report_2013 /photonics_industry_report_2013.pdf

${ }^{2} \mathrm{http}: / / \mathrm{www} \cdot$ photonics21.org/download/News/PhotonicsandTOLAEin Horizon2020.pdf
}

\section{REFERENCES}

Appelle, S. (1998). UFOs and the scientific method. Science 281, 919. doi: $10.1126 /$ science. $281.5379 .919 b$

Archer, T. M. (2008). Response rates to expect from Web-based surveys and what to do about it. J. Exten. 46, 3RIB3. Available online at: http://www.joe.org/joe/ 2008june/rb3.php

Bristish Broadcasting Corp. (2014). The Next Billionaires in Numbers. Available online at: http://www.bbc.com/news/business-27786338

Broad W. J. (2014). Billionaires with Big Ideas are Privatizing American Science. New York, NY: The New York Times. Available online at: funding and support from top institutions and universities would drastically accelerate our understanding of the unexplained light phenomena.

\section{CONCLUSION}

In the 80 's, HL were defined as "UFOs" and were rejected by most scientists. Thanks to the scientific method and the pioneering work of Erling P. Strand, the atmospheric light anomaly observed in the valley of Hessalen in Norway is now slowly gaining the attention of the scientific community and the respect of academic journals. Moreover, UAP were recently measured in other locations in the world, suggesting that the phenomena might be more global than previously anticipated. Since the mechanism creating these lights is completely unknown, further research is needed to better understand the transient luminous phenomena. Supported herein by the interest of a subset of the academic community, we propose that further investigation on UAP/HL through substantial amount of stable and longterm funding could lead to scientific breakthroughs, advance the field of photonics, and thereby contribute to solving key related societal challenges, such as energy generation and energy efficiency, healthy aging of the population, climate change, and security.

\section{AUTHOR CONTRIBUTION}

EC designed the study and wrote the manuscript. PF performed the statistical analysis and wrote the draft of the manuscript.

\section{ACKNOWLEDGMENTS}

We thank Dr. Karim Si-Tayeb, Dr. Heidi Howard, Dr. Roi Gazit, and Dr. Rodolfo Ciuffa for commenting this manuscript. We also thank emeritus Prof. Peter A. Sturrock, Dr. Giancarlo Sportelli, Dr. Massimo Teodorani, Erling P. Strand, and Bjorn G. Hauge for insightful discussions. EC is supported by a Marie Curie Intra-European Fellowship through the European Commission Seventh Framework Programme.

\section{SUPPLEMENTARY MATERIAL}

The Supplementary Material for this article can be found online at: http://journal.frontiersin.org/article/10.3389/feart. 2016.00017 
Cummer, S. A., Briggs, M. S., Dwyer, J. R., Xiong, S., Connaughton, V., Fishman, G. J., et al. (2014). The source altitude, electric current, and intrinsic brightness of terrestrial gamma ray flashes. Geophys. Res. Lett. 41, 8586-8593. doi: 10.1002/2014GL062196

Graydon, O. (2006). A new name in photonics. Nat. Photon. 1:1. doi: 10.1038/nphoton.2006.1

Hauge, B. G. (2007). Optical spectrum analysis of the Hessdalen phenomenon. 1-12. Available online at: http://www.itacomm.net/ph/2007_HAUGE.pdf

Hauge, B. G. (2010). Investigation and analysis of transient luminous phenomena in the low atmosphere of Hessdalen valley, Norway. Acta Astronaut. 67, 1443-1450. doi: 10.1016/j.actaastro.2010.01.019

Hauge, B. G., and Strand, E. P. (2014). A Global Mechanism Creating Low Atmospheric Luminous Cold Plasmas. Vienna: EGU General Assembly, id.15282.

Kestenbaum, D. (1998). Panel says some UFO reports worthy of study. Science 281, 21. doi: $10.1126 /$ science. 281.5373 .21 a

Lowke, J. J., Smith, D., Nelson, K. E., Crompton, R. W., and Murphy, A. B. (2012). Birth of ball lightning. J. Geophys. Res. Atmos. 117:D19107. doi: 10.1029/2012JD017921

Merali, Z. (2015). Search for extraterrestrial intelligence gets a $\$ 100$-million boost. Nature 523, 392-393. doi: 10.1038/nature.2015.18016

Monari, J. (2013). Hessdalen: a perfect natural battery. Italian Committee Project Hessdalen. Available online at: http://www.itacomm.net/ PH/2013_Monari_et-al-en.pdf.

Monroe, M. C., and Adams, D. C. (2012). Increasing response rates to webbased surveys. J. Exten. 50, 6TOT7. Available online at: http://www.joe.org/joe/ 2012december/tt7.php

Paiva, G. S. (2009). Terrestrial gamma-ray flashes caused by neutron bursts above thunderclouds. J. Appl. Phys. 105:083301. doi: 10.1063/1.3089230

Paiva, G. S., and Taft, C. A. (2010). A hypothetical dusty plasma mechanism of Hessdalen lights. J. Atmos. Solar Terres. Phys. 72, 1200-1203. doi: 10.1016/j.jastp.2010.07.022

Paiva, G. S., and Taft, C. A. (2012a). A mechanism to explain the spectrum of Hessdalen Lights phenomenon. Meteorol. Atmos. Phys. 117, 1-4. doi: $10.1007 / \mathrm{s} 00703-012-0197-5$
Paiva, G. S., and Taft, C. A. (2012b). Cluster formation in Hessdalen lights. J. Atmos. Solar Terres. Phys. 80, 336-339. doi: 10.1016/j.jastp.2012.02.020

Pasko, V. P., and George, J. J. (2002). Three-dimensional modeling of blue jets and blue starters. J. Geophys. Res. Space Phys. 107, 1458. doi: 10.1029/2002JA 009473

Pasko, V. P., Inan, U. S., and Bell, T. F. (2000). Fractal structure of sprites. Geophys. Res. Lett. 27, 497-500. doi: 10.1029/1999GL010749

Smirnov, B. M. (1994). Long-lived glowing phenomena in the atmosphere. Phys. Uspekhi 37, 517-521. doi: 10.1070/PU1994v037n05ABEH0 01424

Strand, E. P. (1990). "Project Hessdalen 1984-Final Technical Report: Part I," in 2nd International Symposium on Ball Lightning, Budapest, June 26-28. Available online at: http://www.hessdalen.org/reports/hpreport84.shtml

Sturrock, P. A. (1998). Physical evidence related to ufo reports: the proceedings of a workshop held at the pocantico conference center. Tarrytown, NY: September 29 - October 4, 1997. J. Sci. Explor. 12, 179-229.

Sturrock, P. A. (1999). The UFO Enigma: A New Review of the Physcial Evidence. New York, NY: Warner Books Inc.

Teodorani, M. (2004). A long-term scientific survey of the Hessdalen phenomenon. J. Sci. Explor. 18, 217-251. Availalble online at: http://www. hessdalen.org/reports/scex1802217251.pdf

Zou, Y. S. (1995). Some physical considerations for unusual atmospheric lights observed in Norway. Phys. Scr. 52, 726-730. doi: 10.1088/0031-8949/ $52 / 6 / 022$

Conflict of Interest Statement: The authors declare that the research was conducted in the absence of any commercial or financial relationships that could be construed as a potential conflict of interest.

Copyright (๑) 2016 Caron and Faridi. This is an open-access article distributed under the terms of the Creative Commons Attribution License (CC BY). The use, distribution or reproduction in other forums is permitted, provided the original author(s) or licensor are credited and that the original publication in this journal is cited, in accordance with accepted academic practice. No use, distribution or reproduction is permitted which does not comply with these terms. 